\title{
The breeding biology of Black-billed Parrot Amazona agilis and Yellow-billed Parrot Amazona collaria in Cockpit Country, Jamaica
}

\author{
SUSAN E. KOENIG
}

\begin{abstract}
Summary
Black-billed Parrot Amazona agilis and Yellow-billed Parrot A. collaria are endemic to Jamaica and are restricted to remnant patches of mid-elevation wet limestone forest. Cockpit Country is the stronghold of Black-billed Parrot and is the only region where these two species occur sympatrically in significant numbers. In northern Cockpit Country, Black-billed Parrots nested commonly in degraded and regenerating edge habitat, where natural nesting cavities did not appear to be limiting. Yellow-billed Parrot nests were less abundant in the study area. Black-billed Parrots produced clutches of 3 or 4 eggs and incubation was approximately 24 days. Nestling growth and development were characteristically slow and the nestling period prolonged. Nesting success of both species was low for non-excavating, cavity-nesting species, but successful nests were prolific. Black-billed Parrot nestling mortality was highest during the first four weeks of the nestling period, the primary cause being predation, followed by "dead-in-nest, possible hypothermia". Many aspects of Black-billed and Yellow-billed Parrot nesting behaviour may be related to predation. The majority of predation events were attributed to the endemic and Vulnerable yellow boa Epicrates subflavus. Such predator-prey dynamics will challenge Jamaica's natural resource managers to develop a more comprehensive attitude away from single-species conservation towards multiple species and their interactions in a complex habitat.
\end{abstract}

\section{Introduction}

Jamaica is unique among the islands of the Greater Antilles in hosting two endemic species of Amazona parrot: Black-billed Parrot Amazona agilis and Yellow-billed Parrot A. collaria (Forshaw 1989). Once widespread and common across the island (Gosse 1847, Scott 1891-3, Danforth 1928), both species have declined due to loss and fragmentation of natural forests (Lack 1976, Cruz and Gruber 1981, Cook 1984, Varty 1991). Major populations of both are now restricted to mid-elevation wet limestone forests of the John Crow Mountains and Cockpit Country. This latter region is the stronghold of Black-billed Parrot and is the only region where the two species occur sympatrically in significant numbers. Recent surveys estimated 8,500 \pm 1 , 000 territorial pairs of Black-billed Parrots and 6,500 $\pm 1,500$ of Yellow-billed Parrots for Cockpit Country (Davis 2001), much higher than previous estimates for the entire island ( 1,500 for Black- 
billed Parrots and 2,500 for Yellow-billed Parrots; Gruber 1980). Although Blackbilled Parrots are locally common in Cockpit Country, an area of approximately $500 \mathrm{~km}^{2}$, their almost exclusive restriction to this region renders them vulnerable to continuing deforestation and degradation of forests on Jamaica. Human encroachment continues to alter forest structure and quality, with unknown effects on interactions between parrot species and other resident wildlife. Unlike many mainland parrot species, poaching is minimal; neither species is highly desired in the pet trade and most nestlings are poached for the local market (Wright et al. in press, P. Childers verbally). Both species have been given the IUCN status Vulnerable and are listed on CITES Appendix II (Snyder et al. 2000).

With one of the world's highest rates of deforestation (World Resources Institute 1998-99), the protection of remaining natural habitats on Jamaica is of critical importance (Stattersfield et al. 1998). Continuing deforestation of Cockpit Country will lead to a reduction in food resources, less shelter from inclement weather (e.g. hurricanes) and, perhaps most important for the parrots, a reduction in nesting sites (tree hollows) (see Wiley 1991, Wiley and Wunderle 1993, Wunderle and Wiley 1996). Habitat alteration may change the quality of remaining resources and/or perturb interactions among species. Unfortunately for Jamaica's natural resource managers, there is a dearth of basic natural history and demographic information for the endemic parrots, much less an understanding of the mechanisms that regulate population dynamics within the habitat gradient they occupy. Cruz and Gruber (1981) presented baseline summaries of foraging ecology and reproductive biology for both species, but their fieldwork rarely lasted more than one month (i.e. less than a complete breeding cycle). Other information is limited to anecdotal observations (Downer 1976, Gruber 1985, Hodges 1990). This paper reports new information on the behavioural ecology and reproductive biology of Black-billed Parrots and Yellow-billed Parrots collected during a three-year study (1996-98). This research was one component of a conservation programme developed for Jamaica's Amazona parrots, in collaboration with BirdLife Jamaica and Wildlife Preservation Trust International.

\section{Study area}

A core study area was established on the northern edge of Cockpit Country, Jamaica $\left(18^{\circ} 21^{\prime} \mathrm{N}, 77^{\circ} 38^{\prime} \mathrm{W}\right.$, elevation $100-500 \mathrm{~m}$; Figure 1$)$. The area receives its name from the plateau of hard limestone that has eroded into a series of steep, rocky, conical hills, separated by depressions or "cockpits", each drained by a sinkhole at the bottom. Cockpits have an average depth of 100-120 m, but may be up to $150 \mathrm{~m}$ deep. The dominant forest type is "Wet Limestone Forest" (Asprey and Robbins 1953, Proctor 1986), comparable to "Evergreen Seasonal Forest" of Beard (1944). Late-succession forest canopy height is 15-20 m, except for the occasional emergence of Terminalia latifolia and Cedrela odorata at 25-30 m. Undergrowth is sparse due to poor hillside soil, but lianas, vines, and epiphytes are abundant. Annual temperature ranges from the low $20 \mathrm{~s}$ to mid $30 \mathrm{~s}{ }^{\circ} \mathrm{C}$. Annual rainfall averages $150-200 \mathrm{~cm}$, but is highly seasonal with bimodal peaks in May-June and August-October. January-March is considered the dry period.

The rugged terrain of Cockpit Country and difficulties of access have hindered large-scale exploitation of resources in the interior, but the periphery and sur- 


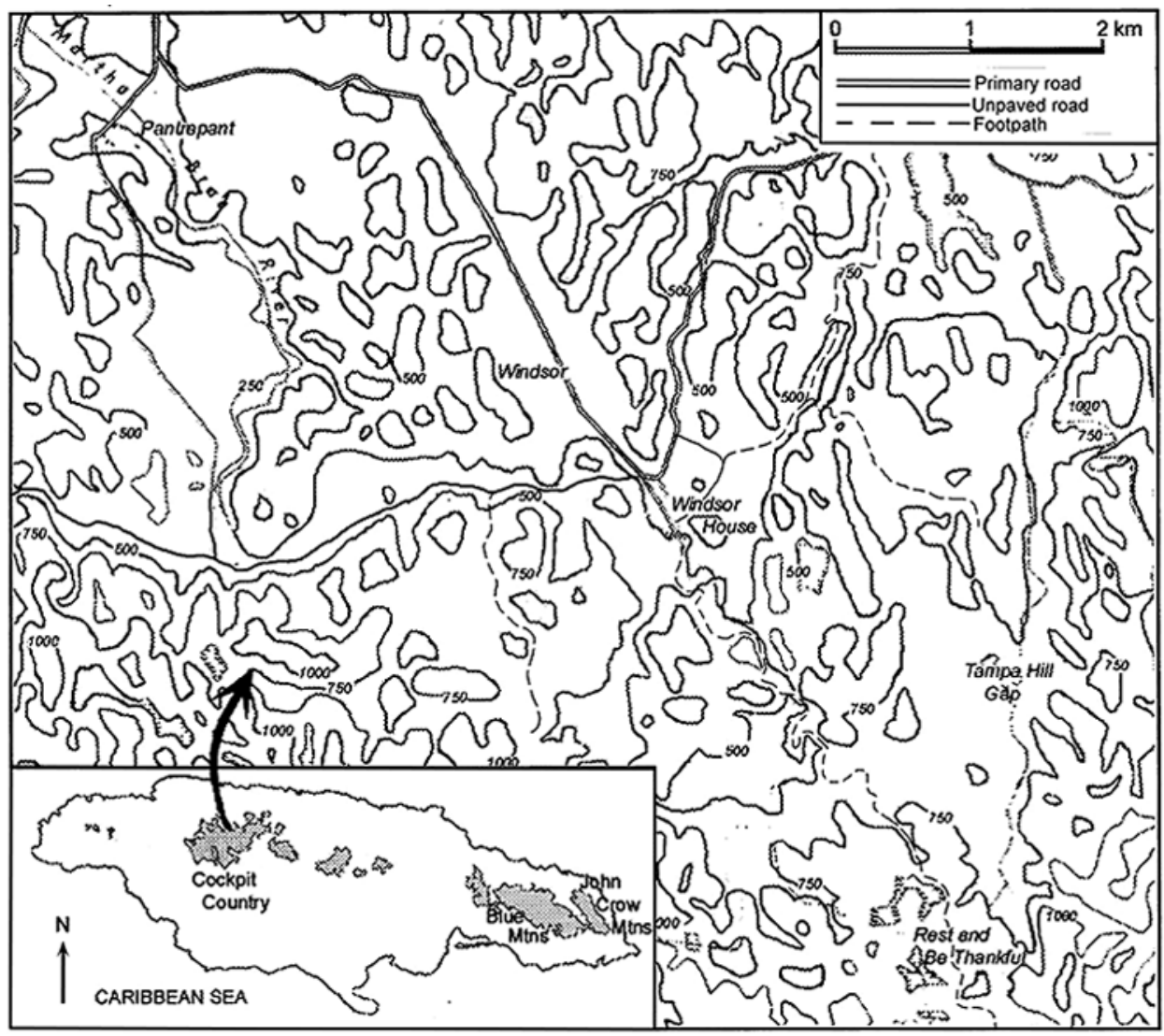

Figure 1. The study area within its regional context of Cockpit Country, Jamaica. Contour line elevations are given in feet, as presented on 1:12,500 survey maps. The inset map highlights the major remnant natural habitats suitable for Black-billed Parrots and Yellowbilled Parrots.

rounding plains are badly degraded. The resultant landscape is a mosaic of four habitat types: (1) disturbed edge used for agriculture (e.g. sugar cane, cattle production), (2) less disturbed edge of regenerating forest, (3) disturbed interior of abandoned agricultural plots in cockpit bottoms and forest cover on hill slopes, and (4) minimally disturbed interior forest. The core study area encompassed habitat structures (1), (2), and (3). Extensive clear-cutting of edge forest for timber occurred in the study area from the mid-1930s until the early $1950 \mathrm{~s}$ (W. Donald-Hill in litt. 2000), and selective cutting of hardwoods continues. Access into the interior forest was via the Troy-Windsor Trail, a 2-m wide trail traversing Cockpit Country on its north-south axis. A system of narrower paths created during the eighteenth and nineteenth centuries allowed access to the regenerating edge habitat.

Black-billed and Yellow-billed Parrots are not distributed evenly across Cockpit Country. Territorial pairs occur at a ratio of 1:1 in the forested centre but Black-billed Parrots occur with greater frequency than Yellow-billed Parrots in 
edge habitats (Davis 2001). On the northern edge of Cockpit Country, Blackbilled Parrot pairs are more abundant than Yellow-billed Parrot at a ratio of 3:1, and in the south by a ratio of 2:1. In the east, however, territorial Yellow-billed Parrots outnumber Black-billed Parrots by 2:1 (Davis 2001).

The study area was selected following pilot surveys around the periphery of Cockpit Country in 1995. The abundance of both species was assessed in order to identify where Black-billed Parrots occurred commonly, as this species is rarer of the two, is more vulnerable because of its restricted range and, consequently, is in greater need of focused conservation efforts. The presence of Yellow-billed Parrot territorial pairs, albeit at lower densities, allowed for comparison between species.

\section{Methods}

Nest searches were initiated in March, when pairs of Black-billed and Yellowbilled Parrots began prospecting and defending potential nest sites, and concluded in late July, the end of the fledging period. Although Black-billed Parrots were observed exploring cavities from late June to July, none of these sites were subsequently used. Trails were walked at daybreak (before parrots departed their roosting sites) and observers remained in an area when characteristic vocalizations of stationary parrots commenced. The locations of territorial pairs (defined as a pair remaining in one location, counter-calling vigorously with another pair) were marked on topographic maps (1:12,500; Survey Department of Jamaica). Duration of counter-call bouts, species identity, and flight movements towards other pairs were recorded. When a member of a pair was observed perched at a cavity entrance, the nest was assigned a number for later measurement of physical characteristics (see Koenig 1999). Nests were rechecked within one week to confirm the presence of eggs. Sites not adopted by the time of the second check were periodically revisited during the breeding season to assess adult activities. During these nest search efforts, opportunistic observations were made of longdistance flight movements from roosting to foraging areas, feeding activity, and any other behaviour not directly associated with breeding activities.

Nests were observed with $15-45 \times 60$ spotting scopes and $8 \times 42$ binoculars in dawn-to-dusk watches ( $5 \mathrm{~h}_{30}-19 \mathrm{hoo}$ ) conducted from camouflaged blinds positioned $10-50 \mathrm{~m}$ from the nest tree. Nest sites were prioritized for observations based on the visibility of the cavity entrance. Six Black-billed Parrot nest sites were monitored intensively over 11 breeding attempts, providing a complete dataset of once-per-week, full-day observations throughout the incubation and nestling periods. An additional 17 nests were monitored once per week while they remained active. Over the three-year study, 97 nest watches totalling 1,310 hrs were made for Black-billed Parrots. For Yellow-billed Parrots, nine nest watches totalling 95 hours were made. Ad libitum field notes were kept to quantify occurrence and duration of adult behaviour within the nest stand, nest tree and nest cavity. The nesting area was determined to be approximately $50 \mathrm{~m}$ radius, based on (1) the distance from the nest tree that pairs perched to engage in territorial vocalizations with other parrots, (2) the location where males roosted and (3) the distance where pairs made their initial perch following their arrival from foraging areas. 
The sex of paired birds was determined by specific behaviour generally associated with each (e.g. female alone incubates). Within pairs, individuals could be distinguished by plumage and behaviour (e.g. Black-billed Parrot males typically had darker ear patches and were not as adept at entering cavities as females; tail and abdominal contour feathers of females became frayed during the incubation period). Although polyvinyl chloride (PVC) legbands have been developed and used successfully on adult parrots in Puerto Rico (Meyers 1995), adults were not ringed for this research owing to the extremely cautious behaviour of both species at their nest sites and the unknown risk of abandonment due to handling. The toenails of neonates were marked with coloured acrylic fingernail polish to enable individual identification. When nestlings were $\geq 5$ weeks old they were banded with unique combinations of open stainless steel bands (DL Products, Arcadia, CA) and coloured PVC bands (see Meyers 1995) for individual identification.

Following hatching, nest sites were checked a minimum of once per week. For those nests too deep to reach nestlings from the cavity entrance, access was gained by cutting $15 \times 15 \mathrm{~cm}^{2}$ doors at the base of the cavity (Stanback and Koenig 1994). Trees were climbed either with climbing ropes and ascenders or via pole steps drilled into trees. After resetting the access door in the tree cut, the edges were sealed with non-toxic caulking to prevent moisture and light penetration into the cavity.

On discovery, eggs were weighed to the nearest $0.5 \mathrm{~g}$ with a $30 \mathrm{~g}$ hanging Pesola scale. Length and breadth were measured to the nearest $0.1 \mathrm{~mm}$ with dial callipers. Egg volume was calculated from Hoyt's (1979) equation: volume = $(0.51) \times($ egg length $) \times(\text { egg width })^{2}$. For Black-billed Parrot nests found during incubation, egg-laying date was calculated from hatching date based on a 24-day incubation period and on the assumption that one egg was laid every other day, the typical pattern of Amazona parrots (Snyder et al. 1987, Enkerlin 1995, pers. obs.). The Black-billed Parrot nesting cycle was divided into discrete phases: (1) egg laying and incubation (24 days), (2) near-continuous brooding (chick age o10 days), (3) early nestling period of maximum growth (days 11-38), (4) midand late-stage plumage development (days 39-56), and (5) post-fledging. These categories correspond to distinct phases of the nesting cycle and offspring development which may have been affected by different causes of mortality (e.g. adults failing to lay eggs, inability of last-hatched chick to compete with older siblings during food provisioning bouts) (see Stoleson and Beissinger 1998). The duration of stages in the Yellow-billed Parrot nesting cycle could not be determined.

Standard nestling measurements (unflattened wing chord, culmen, tarsus, and weight (empty crop)) were collected to monitor nestling growth. Black-billed Parrot growth parameters were modelled using logistic curves (measure = maximum $\left./\left(1+\mathrm{e}^{(-\mathrm{k}(\mathrm{age}))}\right)\right)$, where the maximum growth rates occurred half way between hatching and fledging, and Gompertz curves (measure = maximum $\mathrm{x}$ $\left.\mathrm{e}^{(-\mathrm{e}(-\mathrm{k}(\mathrm{age})))}\right)$ or linear equations (measure $=$ growth/age), when the maximum growth occurred closer to hatching (Ricklefs 1967). Growth data for nestlings, as a function of hatching order and nesting year, were compared using analysis of variance (ANOVA).

Nest contents were checked a minimum of once per week to determine causes 
of mortality. This frequency was necessary to avoid losses of information resulting from the rapid rate of decomposition in the tropics. When nestlings perished, it was noted whether brood loss was partial or total. The nest and nest surrounds were examined to determine the likely cause of mortality. It was rarely possible to confirm the identity of predators with certainty but circumstantial evidence enabled speculation (e.g. mammalian predators such as rats often leave tooth marks on eggs, gnawed remains of nestlings, hair, or faeces; avian predators, such as Jamaican Crow Corvus jamaicensis, destroy eggs; many serpent predators, such as Jamaican yellow boa Epicrates subflavus, rarely take eggs and consume nestlings whole) (see Marini and Melo 1998).

Reproductive performance was assessed using several measures of productivity. After determining clutch size, hatching success, brood size, and fledging success, productivity was expressed as the number of fledglings produced (1) per active nest (those that initiated egg-laying), (2) per successful nest, (3) per egg laid, and (4) per nestling. To calculate daily survival rate and $95 \%$ confidence limits of nesting success, the Mayfield estimator (Mayfield 1975, Johnson 1979) and maximum likelihood estimator (Bart and Robson 1982) were used. A personal computer version of "Program MAYFIELD" (Krebs 1989) was used to calculate the probability of egg or chick survival for the first four stages of the nesting cycle (see above). When fledging was not observed or confirmed through resighting of banded birds, a nestling was classified as fledged if it was at least 50 days old or its crop was fully feathered on the last nest inspection. However, late-stage nest predation should not be discounted.

Data were analysed using SYSTAT (Wilkinson 1990). Means and standard deviations are reported unless noted otherwise. Percentages were arcsinetransformed to normalize distributions (Krebs 1989). Means were compared using ANOVA and $t$-tests. Where significant differences existed $(P<0.05)$, Tukey HSD post-hoc tests were used to identify differences between groups.

\section{Results}

Black-billed Parrot nests were found in greater numbers than Yellow-billed Parrot nests within each of the three habitat types (Table 1). Territorial pairs of Black-billed Parrot were more likely to adopt a site and initiate egg-laying than Yellow-billed Parrot (Table 2). Black-billed Parrots further demonstrated stronger site fidelity in subsequent years. Of 59 trees in which Black-billed Parrots explored cavities, 46 were adopted for use. Seventeen of the 46 were used for multiple seasons: three sites were used over three consecutive seasons and four sites were used twice. A total of 63 nesting attempts were observed for Blackbilled Parrots over the 3-year study period. In contrast, of 12 sites explored by Yellow-billed Parrots, only seven were adopted for use and only one was reused.

\section{Nest searches}

Pairs of both species were found exploring cavity entrances and defending territories surrounding nest sites at least two weeks before the initiation of egg-laying $(n=15)$, but behaviour of the two species differed. Black-billed Parrots vocalized 
Table 1. Number of nest trees used by Black-billed Parrots and Yellow-billed Parrots on the northern edge of Cockpit Country, Jamaica, 1996-98

\begin{tabular}{llll}
\hline Species & \multicolumn{3}{c}{ Habitat type } \\
\cline { 2 - 4 } & $\begin{array}{l}\text { Agriculture edge } \\
(45 \%)\end{array}$ & $\begin{array}{l}\text { Regenerating edge } \\
(30 \%)\end{array}$ & $\begin{array}{l}\text { Disturbed interior } \\
(25 \%)\end{array}$ \\
\hline Black-billed Parrot & 24 & 19 & 3 \\
Yellow-billed Parrot & 0 & 5 & 2 \\
\hline
\end{tabular}

Table 2. Results of nest-searching efforts for Black-billed Parrots and Yellow-billed Parrots in northern Cockpit Country, Jamaica, 1996-98

\begin{tabular}{|c|c|c|c|c|c|c|c|c|}
\hline & \multicolumn{4}{|c|}{ Black-billed Parrot } & \multicolumn{4}{|c|}{ Yellow-billed Parrot } \\
\hline & 1996 & 1997 & 1998 & Total & 1996 & 1997 & 1998 & Total \\
\hline $\begin{array}{l}\text { Date of nest search } \\
\text { initiation }\end{array}$ & $20 \mathrm{Mar}$ & 6 Mar & I Mar & & $20 \mathrm{Mar}$ & 6 Mar & 1 Mar & \\
\hline $\begin{array}{l}\text { Number of territorial } \\
\text { pairs }\end{array}$ & 17 & 32 & 21 & 70 & 3 & 9 & o & 12 \\
\hline $\begin{array}{l}\text { Number of egg-laying } \\
\text { pairs }\end{array}$ & 17 & 31 & 15 & 63 & 2 & 5 & o & 7 \\
\hline $\begin{array}{l}\text { Percentage of pairs } \\
\text { initiating egg-laying }\end{array}$ & $100 \%$ & $97 \%$ & $71 \%$ & $90 \%$ & $67 \%$ & $56 \%$ & - & $58 \%$ \\
\hline
\end{tabular}

Territorial pairs are defined as those in which at least one member of the pair was observed entering a cavity or the female was observed at a cavity entrance displaying pre-egg laying behaviour. Yearly totals include pairs found in previous years. Although birds were not banded, nest sites that were re-used were believed to be occupied by the same birds of the preceeding year based on behavioural idiosyncracies.

in trees in which they were prospecting cavities and remained perched at their nest tree during territorial counter-calling sessions, while Yellow-billed Parrots often perched away from nest trees during calling bouts. Encounters between Black-billed Parrot pairs were never observed to escalate beyond vigorous counter-calling. Black-billed Parrots attempted to encroach on two nests that had been explored by Yellow-billed pairs. They were met with vociferous calling from the Yellow-billed Parrots, and in the case where one Black-billed Parrot perched at the cavity entrance, both members of the resident pair flew and displaced the intruders, suggesting that Yellow-billed Parrots, the larger of the two species, were dominant. Neither of these nests was adopted for use by either species.

In general, both species tended to be much warier around nest trees than other Amazona spp. (Koenig 1994, Enkerlin-Hoeflich 1995) or other psittacines (e.g. Rhynchopsitta pachyrhyncha, Lanning and Shiflett 1983, Koenig unpubl. data). Approach by a human to an active nest tree almost always resulted in flushing birds from the canopy or the female from the nest during incubation and brooding. For Yellow-billed Parrots in particular, observer movement in blinds was typically met with a flurry of alarm calls. Five full-day watches of Yellow-billed nests were terminated mid-morning as pairs refused to enter the nest to feed nestlings. Adults perched within $10 \mathrm{~m}$ of their nest tree and gave periodic outbursts of alarm calls until the observer left the nest stand. Because of the lower number of Yellow-billed Parrot nests located in the study area (conditions which 
should not be extrapolated to their entire range of Cockpit Country), comparative data on breeding biology are limited for this species (Table 3).

\section{Copulation, egg-laying and incubation}

Copulation was observed twice pre-egg laying in Black-billed Parrot, and once during the nestling period (nestling age estimated 40 days) for Yellow-billed. Black-billed Parrot females repeatedly solicited food from their mates, who readily transferred food by regurgitation. Copulation followed the pattern described for Neotropical parrots (Snyder et al. 1987), with the male placing one foot on the female's rump while gripping the perch with the other. Black-billed Parrot copulations lasted 65 and 72 seconds, during which the female perched near the nest tree emitting soft, clucking whines. Vocalizations were not heard from the Yellow-billed pair during copulation.

There was a high degree of synchrony among female Black-billed Parrots in the initiation of egg-laying during each breeding season (Figure 2). Egg-laying interval was approximately 48 hours between successive eggs $(n=5)$, although one female delayed four days between the laying of her second and third eggs. Eggs were white and spherical to elliptical in shape, with one end slightly more pointed than the other. Females began incubating on laying their first egg. Females alone incubated, spending the majority of daylight hours between egglaying and hatching inside the cavity $(\bar{x}=83 \pm 8 \%$, range $64-95 \%, n=143$ observation hours at 11 nests, Figure 3).

Male Black-billed Parrots roosted within $50 \mathrm{~m}$ of the nest tree during incubation, and were either seen flying from the nest tree to roost at night, or heard calling softly before departing for their first feeding of the morning. Males

Table 3. Comparison of Black-billed Parrot and Yellow-billed Parrot breeding biology in northern Cockpit Country, Jamaica, $1996-98$

\begin{tabular}{lll}
\hline & Black-billed Parrot & Yellow-billed Parrot \\
\hline Breeding season & March-August & March-July \\
Mean clutch size & $3.1 \pm 0.5(n=20)$ & $3 \pm 0(n=3)$ \\
Egg characteristics & $33.6 \pm 1.7(n=23)$ & $35.9 \pm 1.1(n=6)$ \\
$\quad$ Length (mm) & $26.5 \pm 0.6(n=23)$ & $28.1 \pm 0.9(n=6)$ \\
Width (mm) & $13.1 \pm 1.4(n=23)$ & $14.3 \pm 0.9(n=6)$ \\
$\quad$ Volume $\left(\mathrm{cm}^{3}\right)$ & $14.9 \pm 0.7(n=13)$ & Unknown \\
Fresh egg mass (g) & $48-72$ hrs between eggs & Unknown \\
Egg-laying pattern & $24(\text { range } 24-26)^{\mathrm{b}}$ & Unknown \\
Incubation period (days) & $13.3 \pm 0.7(n=48)$ & Unknown \\
Mean weight at hatching (g) & $54.6 \pm 2.2(n=12)$ & Unknown \\
Nestling period (days) & $207.9 \pm 12.3(n=18)$ & Unknown \\
Maximum nestling weight (g) & $172.7 \pm 11.4(n=12)$ & $188(185-191)(n=2)$ \\
Fledging weight (g) & & \\
Daily feeding rates & $3.4 \pm 0.5$ & 2 \\
$\quad$ Egg laying and incubation & $3.3 \pm 0.8$ & 2 \\
Hatching and early nestling & $3.3 \pm 1.8$ & \\
Mid- and late-stage nestling & & \\
\hline
\end{tabular}

${ }^{a}$ Weights were taken within three days of egg-laying

${ }^{\mathrm{b}}$ Predicted incubation period based on fresh egg mass is 20 days (Ar \& Rahn 1978) 


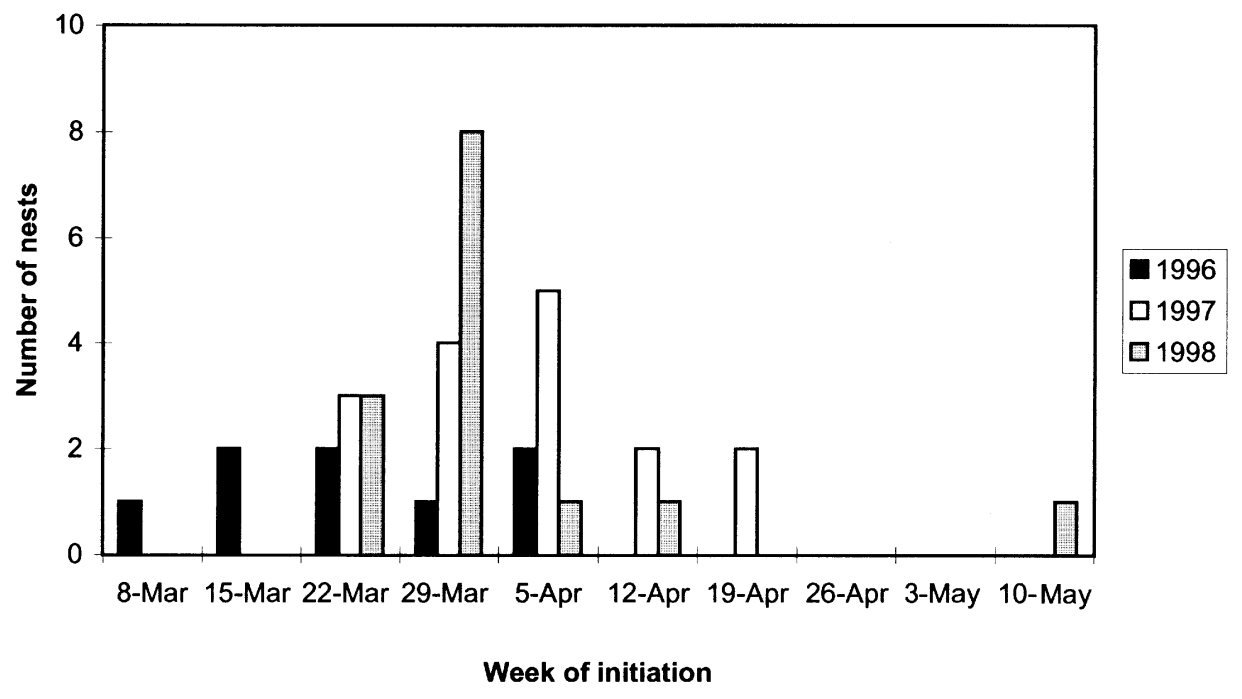

Figure 2. Clutch initiation of Black-billed Parrots in Cockpit Country, Jamaica. Nests found after hatching were not included. The outlier during the week of 1o May is thought to be a first attempt during the breeding season rather than replacement clutching.

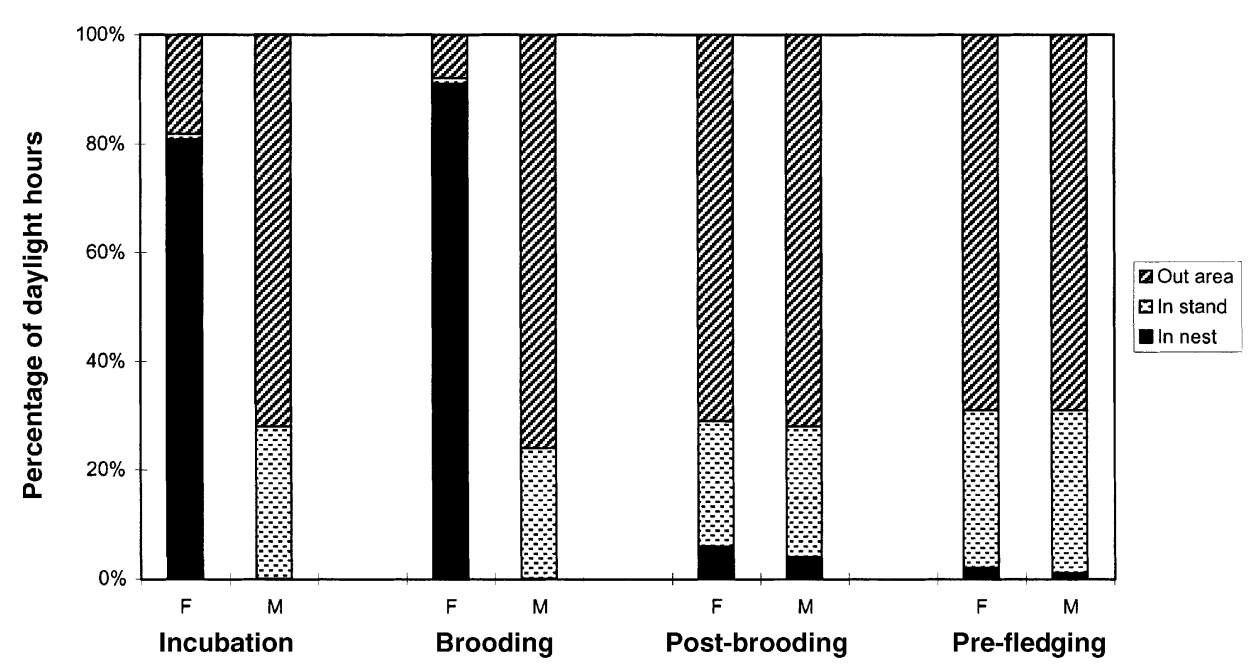

Figure 3. Female (F) and male (M) Black-billed Parrot nest attendance during the stages of incubation (24 days), brooding of young chicks (o-14 days of age), post-brooding period of nestling growth and plumage development (11-50 days of age) and pre-fledging (50+ days of age).

returned to the nest $140 \pm 33$ minutes after sunrise and called to females for the first feeding of the day. Typically males would arrive and perch within $30 \mathrm{~m}$ of the nest tree, call briefly, and then proceed to the nest tree. A soft series of "muhweeps" was usually sufficient to alert the female, who would exit the cavity and take silent flight, followed by the male. Food exchanges were observed between 
10 and $100 \mathrm{~m}$ from the nest tree. During incubation the male fed the female on average three times per day, with food transfers (i.e. time off eggs) lasting $16 \pm$ 6 minutes. Black-billed Parrot females showed little hesitation in entering the nest following their return from a food transfer, taking only $2 \pm 1$ minutes to approach the cavity and enter. On three occasions during the latter half of the incubation period, females remained perched quietly near their cavity entrances during mid-afternoon (13hoo-16hoo), the period when cavity air temperature was highest (Koenig 1999), with no apparent negative consequences to egg viability.

\section{Parental attendance during the nestling period}

Within clutches, eggs of Black-billed Parrots hatched asynchronously in late April and early May. Two to seven days passed between hatching of the first and last eggs. Females ceased near-continuous brooding when the oldest nestling was from 10 to 14 days old. As a result of asynchronous hatching, the youngest chick was typically less than seven days of age when females ceased brooding.

Also during this period, the pair's yearling offspring (confirmed by leg bands $(n=1)$ or assumed if unbanded $(n=2))$ was no longer tolerated in the nest stand when it accompanied the male as he flew to and from the nest stand. During incubation the yearling was permitted to perch at the cavity entrance, but was displaced by directed flight or aggressive lunges during the brooding stage. The yearling was not observed thereafter in the nest stand. At no nest was more than one yearling observed with the parents.

Male attendance of the female during near-continuous brooding was similar to that during incubation (Figure 3). Females were fed a similar number of times at both stages $(t=0.596, d f=16, P=0.560$; Table 3$)$ and the duration of feeding bouts was not significantly different between the periods of incubation and nearcontinuous brooding $(t=1.142, d f=9, P=0.283)$. However, behaviour of the female did change as eggs began hatching. Whereas during incubation females showed little hesitation entering the nest on return from a food transfer bout, they became warier during the brooding period. It took them an average of $9 \pm$ 11 minutes to enter the nest, in contrast to the $2 \pm 1$ minutes during incubation $(t=2.227, d f=16, P=0.04)$. Qualitatively, females approached the cavity entrance with greater caution, peered around the area and made multiple aborted attempts before entering the cavity.

\section{Post-brooding}

Cessation of near-continuous brooding was marked by Black-billed Parrot females foraging with their males during the morning hours but brooding young in the afternoon and evening and roosting in the cavity overnight. By the time the oldest nestling was three weeks old, females no longer brooded in the afternoon and roosting in the cavity ceased (Figure 3). Nest attendance decreased during this period, with adults spending less than one hour ( $43 \pm 26$ minutes) in the nest per day. Adults continued to return to the nest three times per day to feed chicks, with an average feeding bout lasting $12 \pm 8$ minutes. As with other Greater Antillean Amazona species, adults showed strong within-pair cohesion in 
their movement patterns during this period (Snyder et al. 1987, Gnam 1991, J. Wiley verbally). During an attendance bout, both adults typically entered the cavity, although not simultaneously, to feed chicks, with males being distinguished easily by their clumsier attempts to descend. The adults' hesitancy to enter the cavity following arrival at the nest tree continued to increase during this post-brooding period. On average a member of the pair (usually the female first) waited $29 \pm 21$ minutes to enter the cavity. As during the brooding period, her behaviour was punctuated with repeated aborted attempts to enter the cavity and brief outbursts of perched and alarm calls.

Parental attendance patterns changed in the week before the first chick fledged. Adults spent significantly less time in the nest feeding chicks compared with the amount of time they spent in the nest during the post-brooding stage $(\bar{x}=7 \pm 4$ minutes, $t=2.143, d f=35, P=0.03$ ). At this stage, adults would sit near the cavity entrance and vocalize softly. Nestlings would come to the entrance and, after prolonged begging, the parents would lean into the entrance to feed them, but food transfer was minimal. Examination of crop distension in nestlings following the adults' departure from the nest stand confirmed these observations.

Black-billed Parrot chicks fledged typically within four days of making their first appearance at the entrance. Of nine fledglings observed, $71 \%$ occurred before 10 hoo and all when the parents were present in the nest tree. Typically, the nestling appeared at the entrance, stretched its head several times towards the parents and then silently flew from the nest. Flight appeared relatively strong and coordinated. However, manoeuvrability was poor and landing resulted from collision with the first obstacle in the flight line. Once the fledgling perched, the adults immediately fed it. After their maiden flight, fledglings made several more short flights during the day, with the adults commuting between the fledgling and remaining nestlings for feeding bouts.

\section{Nestling growth and development}

Black-billed Parrot neonates were altricial. At hatching, eyes and ears were fused, muscular development was insufficient to maintain the head erect and only a small amount of white down was present. Eyes began to open from 8 to 10 days but were not fully open until 11 to 14 days. Ear openings also became visible at this time.

Two distinct phases were recognized during the nestling period: early growth and late plumage development. The first part of the nestling phase was characterized by near-linear growth, which peaked at $38 \pm 3$ days post-hatching, slightly more than one half of the nestling period (Figure 4, Table 4). Towards the latter part of this stage, at approximately 21 days, quills on wing coverts and primaries began to emerge. Feathers did not begin to unsheathe until the second half of the growth phase, demarcated by both feather development and a decrease in body weight. Downer and Sutton (1990) noted red feathers in wing coverts of adults as a distinguishing field mark, but these feathers emerged during the nestling period. Broods showed variation of this feature, with all or some proportion of nestlings having red or green primary coverts. It was not, however, a sexually dimorphic characteristic at adulthood as both members of some reproductively active pairs were observed with red feathers in their wing coverts. 

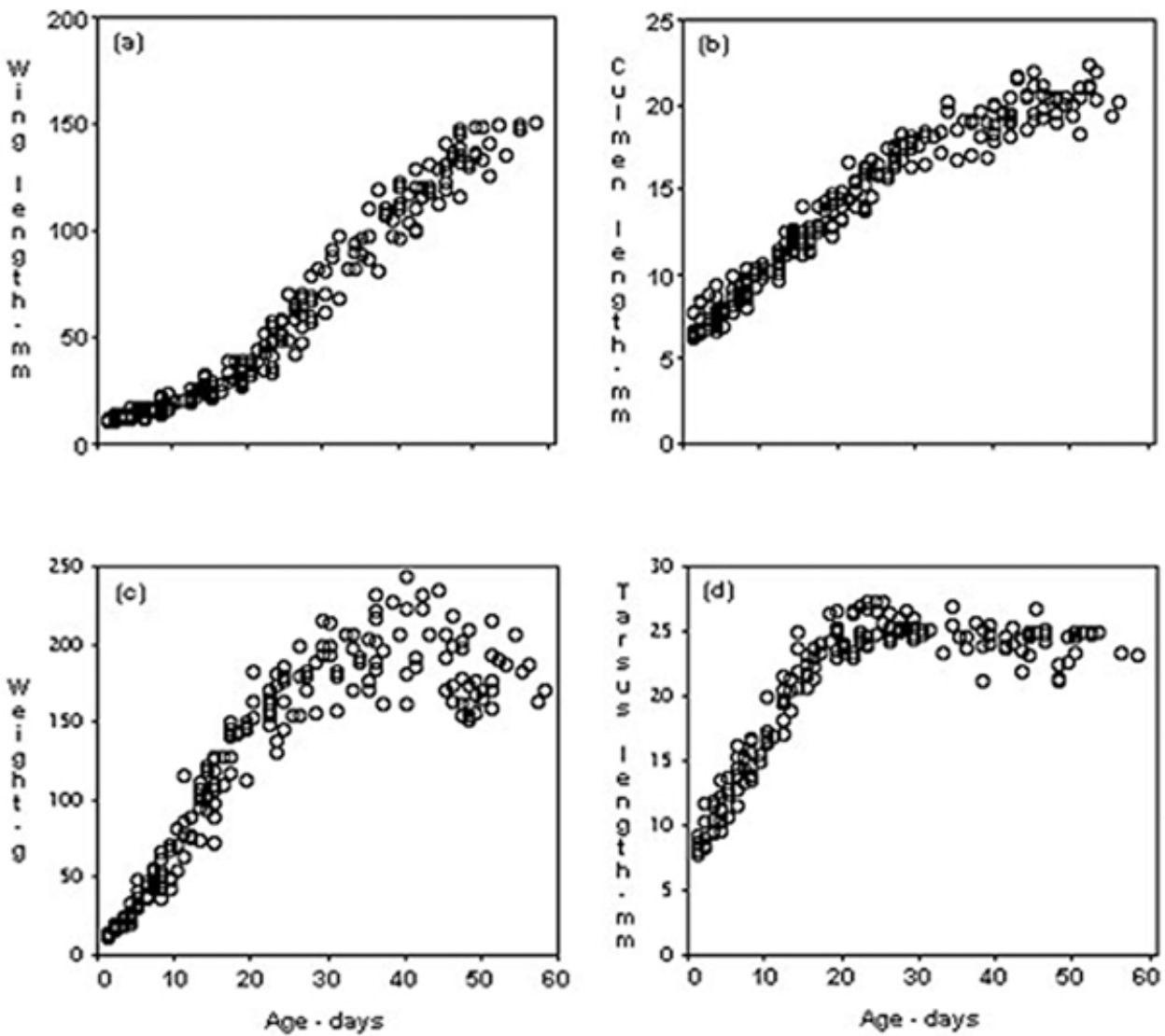

Figure 4. Changes of (a) weight, (b) tarsus length, (c) flattened wing chord and (d) culmen length of Black-billed Parrot nestlings in Cockpit Country, Jamaica, 1996-98. Data points are of known-age nestlings in broods of two and three.

Table 4. Growth parameters as functions of hatching order of Black-billed Parrots in northern Cockpit Country, Jamaica, 1996-98

\begin{tabular}{|c|c|c|c|}
\hline & $\begin{array}{l}\text { Nestling I Mean } \\
\pm \text { SD }(n)\end{array}$ & $\begin{array}{l}\text { Nestling } 2 \text { Mean } \\
\pm \text { SD }(n)\end{array}$ & $\begin{array}{l}\text { Nestling } 3 \text { Mean } \\
\pm \text { SD }(n)\end{array}$ \\
\hline Age at maximum weight (days) & $40.5 \pm 2.8(7)$ & $37.2 \pm 2.2(5)$ & $35.8 \pm 5.2(6)$ \\
\hline Maximum nestling weight (g) & $220.6 \pm 13.3(7)$ & $211.8 \pm 11.7(5)$ & $191.3 \pm 13.1(6)$ \\
\hline Fledging weight $(\mathrm{g})$ & $178.0 \pm 11.3(3)$ & $177.8 \pm 19.1(5)$ & $161.5 \pm 6.9(4)$ \\
\hline \multicolumn{4}{|l|}{ Growth rate $(k)$} \\
\hline \multicolumn{4}{|l|}{ Logistic } \\
\hline Wing chord & 0.099 & 0.096 & 0.094 \\
\hline Culmen & 0.103 & 0.103 & 0.095 \\
\hline \multicolumn{4}{|l|}{ Gompertz } \\
\hline Weight & 0.105 & 0.109 & 0.113 \\
\hline \multicolumn{4}{|l|}{ Linear } \\
\hline Tarsus $^{\mathrm{a}}$ & 0.952 & 0.870 & 0.913 \\
\hline
\end{tabular}

${ }^{a}$ Maximum length reached at 25 days of age; growth terminated or decreased slightly to fledging. 
The growth of wing and culmen followed logistic growth patterns while increases in weight followed the Gompertz equation (Figure $4 \mathrm{a}-\mathrm{c}$ ). Tarsus growth was linear until maximum length was reached at 25 days (range 21-27). Thereafter, growth ceased or was slightly negative as fat deposits were reduced in the foot (Figure $4 \mathrm{~d}$ ). The age at which nestlings reached their maximum weight was not significantly different among first-hatched chicks and subsequent siblings $\left(\overline{\mathrm{x}}=38.8 \pm 4.7\right.$ days, $\left.F_{2,15}=2.040, P<0.165\right)$ but there was a significant difference in the maximum weight of nestlings as a function of hatching order $\left(F_{2,13}=6.744\right.$, $P<0.010$; Table 4). The maximum weight of the third-hatched nestling was significantly lower than the weight of the first-hatched chick (Tukey HSD test, $P$ $<0.008)$ and was close to being significantly different from the weight of the second-hatched chick (Tukey HSD test, $P<0.070$ ). There was no significant difference between the maximum weights of the first- and second-hatched nestlings (Tukey HSD test, $P<0.489$ ). The weight at which nestlings fledged did not differ as a function of hatching order, despite the trend of the third-hatched nestling to weigh less (grouped nestling $\bar{x}=172.4 \pm 11.3 \mathrm{~g}, F_{2,8}=1.577, P<0.265$ ). When nestling data were pooled, the age at which nestlings reached their maximum weight did not vary significantly between years $\left(F_{2,13}=0.029, P<0.971\right)$, nor did their weight at fledging vary between years $\left(F_{2,19}=0.264, P<0.770\right)$. However, the age at which nestlings fledged varied significantly $\left(F_{2,19}=3.845, P<0.040\right)$, with chicks fledging at an earlier age in $1998(\bar{x}=52.6 \pm 0.5$ days, Tukey HSD test, $P<0.033)$ compared with $1996(\overline{\mathrm{x}}=55.9 \pm 1.5$ days $)$ and $1997(\overline{\mathrm{x}}=54.8 \pm 2.7$ days, Tukey HSD test, $P<0.549$ ).

\section{Nest failure and nestling mortality}

Of the 63 nesting attempts by Black-billed Parrots, 35 failed before producing at least one fledging. Egg-laying pairs had an overall nesting success of $42 \pm 13 \%$ (Table 5). Causes of nest failure varied, but predation of nestlings accounted for over a third (to nearly 50\%) of total nest failures (Table 6). Although direct evidence of predator identity was limited, most evidence strongly suggested predation by yellow boas. Direct evidence included the capture of a yellow boa in a Black-billed Parrot nesting cavity, the snake having consumed two of the three chicks (R. Diesel, verbally), and the legbands of a recently fledged Yellow-billed Parrot found in a snake faecal pellet $3 \mathrm{~m}$ from the nest tree along with a shed snake skin. This nest was used the following year by Yellow-billed Parrots and failed during the nestling period, with a shed snake skin found at the cavity entrance. Only two Black-billed Parrot nests failed during incubation. At one site, $30 \mathrm{~m}$ from the field house, the female abandoned her nest with a flurry of alarm squawks at 04 hoo, presumably flushed by a predator. Her two eggs were buried $3 \mathrm{~cm}$ in the substrate but were intact. The pair was not seen again in the nest stand. The second failed site was a direct result of researcher activities while cutting an access door, which led to destruction of the nest contents.

The percentage of Black-billed Parrot eggs that hatched did not vary significantly between years $\left(\bar{x}=85 \pm 28 \%, n=37, F_{2,34}=1.014, P<0.318\right)$. Mayfieldestimated finite probabilities of eggs or chicks surviving each stage delineated the period when nest contents were most vulnerable: (1) egg-laying/incubation period $=0.74,(2)$ near-continuous brooding $=0.75$, (3) partial brooding, early 


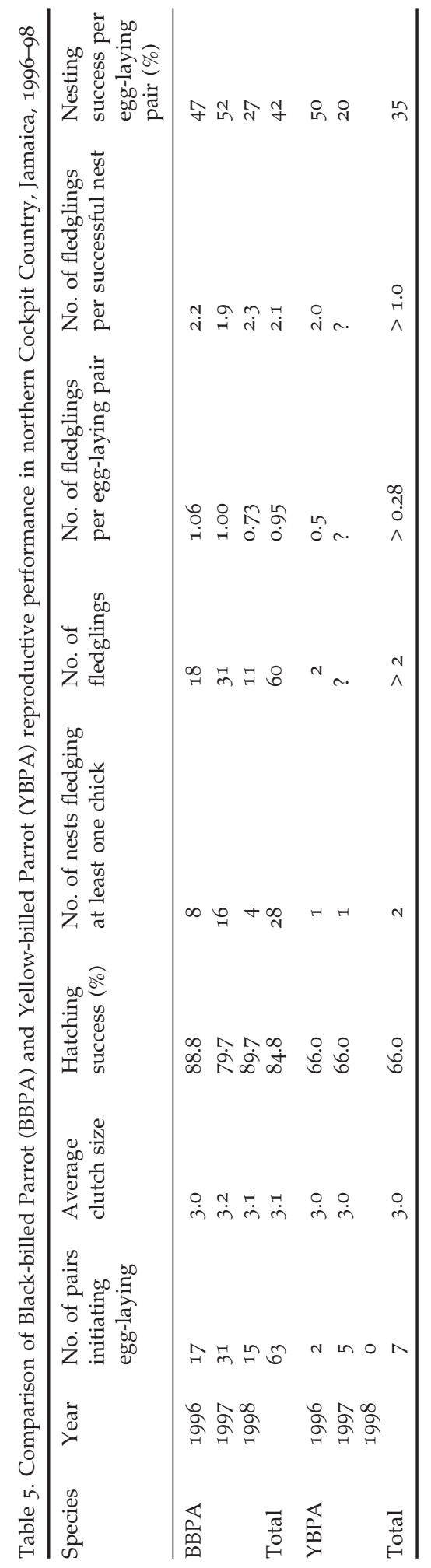


Table 6. Causes of Black-billed Parrot nest failure for sites that failed before fledging at least one chick, in Cockpit Country, Jamaica, 1996-98

\begin{tabular}{llllllll}
\hline Year & \multicolumn{6}{c}{ Cause of failure $n(\%)$} \\
\cline { 2 - 8 } & $\begin{array}{l}\text { Eggs } \\
\text { abandoned }\end{array}$ & Predation & $\begin{array}{l}\text { Dead-in-nest } \\
\text { (poss. exposure } \\
\text { and hypothermia) }\end{array}$ & $\begin{array}{l}\text { Starvation } \\
\text { because } \\
\text { abandoned }\end{array}$ & Poached & Unknown & $\begin{array}{l}\text { Researcher } \\
\text { impact }\end{array}$ \\
\hline 1996 & $1(11 \%)$ & $1(11 \%)$ & $2(22 \%)$ & 0 & $1(11 \%)$ & $4(44 \%)$ & 0 \\
1997 & $1(7 \%)$ & $7(47 \%)$ & $4(27 \%)$ & 0 & 0 & $2(13 \%)$ & $1(7 \%)$ \\
1998 & $1(9 \%)$ & $5(45 \%)$ & $3(27 \%)$ & $1(9 \%)$ & 0 & $1(9 \%)$ & 0 \\
Total & $3(8 \%)$ & $13(37 \%)$ & $9(26 \%)$ & $1(3 \%)$ & $1(3 \%)$ & $7(20 \%)$ & $1(3 \%)$ \\
\hline
\end{tabular}

Values are presented as the total number of nests in each category and the proportional relationship to total nest failure

period of nestling growth $=0.44$, and (4) late period of nestling development to fledging $=0.81$. The overall probability of a nestling surviving from the period of egg-laying to fledging was 0.37 .

Thirteen of the 28 Black-billed Parrot nests that successfully fledged at least one chick suffered brood reduction. Four nestlings died within days of hatching during the brooding period and all had been the last-to-hatch chick. In each instance, the oldest sibling in the clutch was $>8$ days of age and, therefore, much larger in size and mass than the chick that perished. Starvation of last-hatched chicks appeared to be a result of inequitable distribution of food rather than the inability of parents to provide it. Two broods suffered losses from predation of individual chicks while their siblings were left alive. Seven nestlings died in the latter half of the post-brooding phase. The cause of this latter mortality could not be determined but it was suspected that several nestlings died due to a combination of exposure and insufficient energy reserves to thermoregulate. Parents ceased feeding nestlings in the day(s) before fledging, presumably to "encourage" chicks to leave the nest. Younger siblings, however, continued to receive food during the fledging period of older chicks, as confirmed by examination of nestlings after the adults departed the nest stand and all chicks returned to the cavity substrate. At several sites, this "starvation to fledge" coincided with a period of heavy rains. Younger chicks, still being fed, survived but the older nestling perished, suggesting mortality was caused by the combination of adverse weather (thermal stress) and inadequate energy resources.

\section{Discussion}

This study was undertaken to collect baseline natural history information and identify the factors that may limit reproduction of Black-billed Parrots and Yellow-billed Parrots in the northern edge of Cockpit Country, Jamaica. Comparison with other Amazona species assisted in distinguishing local conditions from characteristically inherent traits of psittacines.

Black-billed Parrots nested in high numbers in disturbed and regenerating edge habitats, and did not seem limited by nest cavity availability, as several cavities explored or used successfully one season were left vacant the following year. Additionally, although pairs counter-called vigorously while nest pro- 
specting, these bouts never escalated to physical conflicts between conspecific pairs as in other psittacines in which nest sites are thought to be limiting (Snyder et al. 1987, Munn 1991, Waltman and Beissinger 1992). Agonistic interactions were observed between species on several occasions, with Yellow-billed Parrots dominating Black-billed Parrots, suggesting that nest site availability may be more of a limiting factor for Yellow-billed Parrots in the study area. Cruz and Gruber (1981) suggested that Yellow-billed Parrots required larger trees in which to successfully rear young, and this may account for their lower numbers in the study area, which had been logged heavily in the 1930s through to the early 1950s. Low sample sizes of Yellow-billed Parrot nests precluded statistical comparison of nest dimensions. The degree to which the larger Yellow-billed Parrot may competitively exclude Black-billed Parrots from nest sites remains unclear and further research is needed in the interior forest where species occur in a 1:1 ratio. Effective management of nesting resources within Cockpit Country will require a better understanding of minimal and optimal nest site parameters for Yellow-billed Parrots, particularly if mature forest with larger-diameter trees are important.

During 1996 and 1997, Black-billed Parrot breeding pairs did not appear to be limited by availability of food resources, as monitored via parental provisioning and nestling growth rates. It is not clear why dramatically fewer pairs of Blackbilled and Yellow-billed Parrots attempted to breed in 1998 (Table 2). Pairs that bred did not appear to have difficulties in providing adequate food to nestlings (see Koenig 1999), and, although in 1998 chicks fledged several days earlier than in 1996 and 1997, their maximum and fledging weight did not differ between years. Furthermore, no differences were observed in the frequency of daily feeding visits between years. One nest failed because of abandonment and subsequent starvation of nestlings in 1998, but growth of the three nestlings was not discernibly slower prior to abandonment by both adults, which occurred when nestlings were approximately 5 weeks of age.

Variation in growth rates occurred as a function of hatching order, although this difference was only apparent with respect to third-hatched nestlings. Firstand second-hatched nestlings varied little in size and growth, regardless of whether they were in a brood of two or three. Although youngest chicks failed to attain the maximum mass of older siblings during the nesting period, their smaller size and fledging weight did not appear to affect their survival to fledging, a pattern observed elsewhere for Neotropical psittacines (Renton 1998, Stoleson and Beissinger 1997). Starvation of youngest chicks was common in broods of four, but appeared to be a result of inequitable distribution of food among siblings as a direct result of size disparities associated with asynchronous hatching, rather than a function of food limitation. This contrasts with the brood reduction observed for Australian cockatoos, in which last-hatched chicks frequently died of starvation because of adults' inability to provision adequately (Saunders 1982, Smith and Saunders 1986).

The twice-daily feeding visits of Yellow-billed Parrots (Table 3) were identical to the number of visits observed for four species of mainland Amazona in Mexico (Enkerlin-Hoeflich 1995, Renton 1998). Visiting rates of Black-billed Parrot, the smallest member of the genus, fall between these and the five or more visits made by island Amazona spp. (Snyder et al. 1987, Koenig 1994, Wilson et al. 1995). 
This may be a function of the lower elevation and higher ambient temperatures of the study area compared with the habitat of Puerto Rican Parrot Amazona vittata or other Lesser Antillean species. It may also be that the activities of parrots in Cockpit Country are restricted during the hot, midday period, as has been observed for large cockatoos in dry areas of Australia, and Amazona spp. in Mexico (Saunders 1982, Renton 1998). Black-billed Parrot and other West Indian parrots also differed in the time spent in the nest tending late-stage nestlings. Unlike Puerto Rican Parrots or Red-necked Parrots A. arausiaca of Dominica, Black-billed Parrots did not appear to preen young in the nest cavity and food provisioning bouts remained brief (Snyder et al. 1987, Koenig 1994). Black-billed Parrots appear to minimize the time spent in the nest cavity at later stages.

Female Black-billed Parrots ceased roosting at night in the nest cavity at the same time as they ceased partial daytime brooding of nestlings. This transition occurred when the oldest nestling was approximately three weeks of age. Cessation of continuous brooding reflects the changing thermoregulatory and nutritional demands of the young countered against the energetic maintenance costs of the female (i.e. the food demands of the brood reach a level that the male alone cannot meet) (Drent and Daan 1980, Weathers 1996). The cessation of roosting by Black-billed Parrots may be a behavioural adaptation associated with the risk of predation in the nest (e.g. Weathers and Sullivan 1989, Martin 1992). Overall nesting success for Black-billed Parrots was low compared with island Amazona parrots that nest in tree hollows, which typically have success rates of $60-70 \%$ (Snyder et al. 1987). Predation appeared to be the main factor limiting reproduction of Black-billed Parrots in the northern edge of Cockpit Country. Although incubation proved to be a relatively safe period for adult females, with $<3 \%$ of nests failing during this stage, as eggs began hatching, predation of nest contents increased. Females were able to climb quickly from their nests and avoid predation, as evidenced by the 04 hoo departure of one Black-billed Parrot female. Young nestlings, however, were physically incapable of climbing out of the nest cavity, which often exceeded $200 \mathrm{~cm}$ in depth (Koenig 1999). If predation is the primary cause of nest failure for Black-billed Parrots, as it is with most birds (Ricklefs 1969, Skutch 1985, Martin 1992, Newton 1988), this may also explain the greater similarity of vigilant behaviour to mainland Amazona, where predation, particularly by snakes, has been documented at greater frequency than for island parrots (Enkerlin et al. 1992).

Predation of parrots by Jamaica's yellow boa presents a complex conservation challenge for natural resource managers. The yellow boa is endemic to Jamaica and is the largest native terrestrial predator. As habitat loss has contributed to the decline and isolation of parrot populations, so too has it led to isolated populations of yellow boas. Its conservation status is "Vulnerable" and it is persecuted heavily by fearful humans (Groombridge 1993). Cockpit Country is considered to be the stronghold of the yellow boa and nestling parrots represent one important prey item (Oliver 1982, Prior and Gibson 1997, Koenig 1998). While there are no published data on the density of yellow boas in Cockpit Country, I have captured, marked, and released 27 boas in the degraded edge and regenerating edge habitats of the study area since 1995. An additional two carcasses, killed with machete, have been found in interior forest. High predation rates of parrot nests in edge habitat may be a function of high densities of yellow boas, which 
may be artificially maintained by access to a reliable prey base associated with human activities (e.g. non-native rat Rattus spp.). Alternatively, boas may benefit from the structural complexity of edge habitat (Chandler and Tolson 1990). To what extent regenerating edge forest represents sink habitat for parrots and source habitat for yellow boas is not clear. Further research is needed to evaluate the predator-prey dynamics of these endemic and vulnerable species, with particular attention as to how human modifications of the habitat mediates interactions.

\section{Acknowledgements}

I gratefully acknowledge the permission granted by the Government of Jamaica to study their endemic parrots. I conducted this research under the Jamaica Parrot Project (JPP), a collaborative conservation programme established by BirdLife Jamaica and Wildlife Preservation Trust International (WPTI). The JPP was supported by funding from WPTI, the Environmental Foundation of Jamaica, the Denver Zoological Society, and an anonymous donor. Additional support was provided by Jamaica's Natural Resources Conservation Authority and the Institute of Jamaica. Corporate sponsorship was provided by Air Jamaica. I received a Dissertation Improvement Grant and a G. E. Hutchinson Fellowship from Yale University. Elizabeth Stone, DVM served as veterinary consultant. I am indebted to the following for their field assistance: George Armistead, Garfield Basant, Alan Craig, Herlitz Davis, Chandra Degia, Rosalind Fredericks, Ciaran Hannan, "Jackdaw" Ingram, Jim Shiflett, and Sarah Swope. In addition to his assistance in the field, I thank Noel Snyder for his guidance, comments, and unwavering enthusiasm. Several people deserve meritorious thanks for "adopting" this homeless biologist: Catherine and Charles Levy, Bob and Dian Rattner, and Michael Schwartz. William Donald-Hill kindly outlined the history of Windsor Estate 1892-1953. Oswald Schmitz, David Skelly, and Jim Wiley gave constructive criticisms on early drafts of this manuscript. I thank Stephen Garnett and Gabriel Crowley for their comments as referees.

\section{References}

Ar, A. and Rahn, H. (1978) Interdependence of gas conductance, incubation length, and weight of the avian egg. Pp. 227-236 in J. Piiper, ed. Respiratory function in birds, adult and embryonic. Berlin: Springer-Verlag.

Asprey, G. F. and Robbins, R. G. (1953) The vegetation of Jamaica. Ecol. Monogr. 23: 359412.

Bart, J. and Robson, D. S. (1982) Estimating survivorship when the subjects are visited periodically. Ecology 63: 1078-1090.

Beard, J. S. (1944) Climax vegetation in tropical America. Ecology 25: 127-158.

Bucher, T. L. (1983) Parrot eggs, embryos, and nestlings: patterns and energetics of growth and development. Physiol. Zool. 56: 465-483.

Chandler, C. R. and Tolson, P. J. (1990) Habitat use by a boid snake, Epicrates monensis, and its anoline prey, Anolis cristatellus. J. Herp. 24: 151-157.

Cook, J. M. (1984) Jamaican Amazona parrot expedition. Unpubl. report to ICBP.

Cruz, A. and Gruber, S. (1981) The distribution, ecology, and breeding biology of Jamaican amazon parrots. Pp. 103-131 in R. F. Pasquier, ed. Conservation of new world parrots. 
Washington, D.C.: Smithsonian Institution Press for the International Council of Bird Preservation (Techn. Publ. 1).

Danforth, S. (1928) Birds observed in Jamaica during the summer of 1926. Auk 45: 480491.

Davis, H. A. (2001) Distribution and population size of Amazona parrots in the Cockpit Country, a limestone karst region of Jamaica. Unpubl. master's thesis, University of the West Indies.

Downer, A. (1976) Cockpit Country. Gosse Bird Club Broadsheet 27: 14.

Downer, A. and R. Sutton (1990) Birds of Jamaica. Cambridge, U.K.: Cambridge University Press.

Drent, R. H. and Daan, S. (1980) The prudent parent: energetic adjustments in avian breeding. Ardea 68: 225-252.

Dunn, E. H. (1975) The timing of endothermy in the development of altricial birds. Condor 77: 288-293.

Enkerlin-Hoeflich, E. C. (1995) Comparative ecology and reproductive biology of three species of Amazona parrots in northeastern Mexico. PhD thesis, Texas A\&M University.

Enkerlin-Hoefflich, E. C. and Hogan, K. M. (1997) Red-crowned Parrot. Pp. 1-20 in A. Poole and F. Gill, eds. The birds of North America, 62. Philadelphia, PA: Academy of Natural Sciences.

Enkerlin-Hoefflich, E. C., Whiting, M. J. and Coronado-Limón, L. (1992) Attempted predation on chicks of the threatened Green-cheeked Amazon parrot by an indigo snake. The Snake 25: 141-143.

Forshaw, J. M. (1989) Parrots of the world. Third edition. Melbourne, Australia: Lansdowne Editions.

Gnam, R. (1991) Breeding biology of the Bahama Parrot (Amazona leucocephala bahamensis). Ph.D. dissertation, The City University of New York.

Gosse, P. H. (1847) The birds of Jamaica. London: John Van Voorst.

Groombridge, B., ed. (1993) IUCN Red list of threatened animals. Gland, Switzerland and Cambridge, U.K.: IUCN.

Gruber, S. (1980) Jamaican Amazon parrots. Gosse Bird Club Broadsheet 34: 14.

Gruber, S. (1985) Black-billed Parrot slaughter. Gosse Bird Club Broadsheet 45: 12.

Hodges, M. (1990) Birds at Sterling Castle, St Andrew in 1961 and 1990. Gosse Bird Club Broadsheet 55: 11-14.

Hoyt, D. F. (1979) Practical methods of estimating volume and fresh weight of bird eggs. Auk 96: 73-77.

Johnson, D. H. (1979) Estimating nest success: the Mayfield method and an alternative. Auk 96: 651-661.

Koenig, S. E. (1994) The reproductive biology of Dominica's Amazon parrots. Unpubl. report to Wildlife Preservation Trust International.

Koenig, S. E. (1998) Snake predation on Jamaica's Yellow-billed Parrot. Jamaica Nat. 5: 36.

Koenig, S. E. (1999) The reproductive biology of Jamaica's Black-billed Parrot (Amazona agilis) and conservation implications. DFES Dissertation, Yale University.

Krebs, C. J. (1989) Ecological methodology. New York: Harper Collins.

Lack, D. (1976) Island biogeography: illustrated by the land birds of Jamaica. Oxford: Blackwell Scientific.

Lanning, D.V. and Shiflett, J. T. (1983) Nesting ecology of Thick-billed Parrots. Condor 85: 66-73.

Lambert, F., Wirth, R., Seal, U. S., Thomsen, J. B. and Ellis-Joseph, S. (1993). Parrots: an action plan for their conservation 1993-1998. Unpubl. draft no. 2. Cambridge, U.K.: ICBP Parrot Specialist Group.

Marini, M. A. and Melo, C. (1998) Predators of quail eggs, and the evidence of the remains: implications for nest predation studies. Condor 100: 395-399. 
Martin, T. E. (1992) Nest predation and reproductive strategies. Pp. 163-197 in D. M. Power, ed. Current ornithology 9. New York: Plenum Press.

Martuscelli, P. (1995) Ecology and conservation of the Red-tailed Amazon Amazona brasiliensis in southeastern Brazil. Bird Conserv. Internatn. 5: 405-420.

Mayfield, H. (1975) Suggestions for calculating nest success. Wilson Bull. 87: 456-466.

Mertens, J. A. L. (1977) Thermal conditions for successful breeding in great tits (Parus major). Oecologia 28: 1-30.

Meyers, J. M. (1995) A colored leg banding technique for Amazona parrots. J. Field Orn. 66: $582-589$.

Munn, C. A. (1992) Macaw biology and ecotourism, or "When a bird in the bush is worth two in the hand". Pp. 47-72 in S. R. Beissinger and N. F. R. Snyder, eds. New world parrots in crisis. Washington, D.C.: Smithsonian Institution Press.

Newton, I. (1998) Population limitation in birds. San Diego, CA: Academic Press.

Oliver, W. L. R. (1982) The coney and the yellow snake: the distribution and status of the Jamaican hutia Geocapromys brownii and the Jamaican boa Epicrates subflavus. Dodo, J. Jersey Wildl. Preserv. Trust 19: 6-33.

Prior, K. A. and Gibson, R. C. (1997) Observations on the foraging behavior of the Jamaican boa, Epicrates subflavus. Herp. Review 28: 72-73.

Proctor, G. R. (1986) Cockpit Country and its vegetation. Pp. 43-47 in D. A. Thompson, P. K. Bretting and M. Humphreys, eds. Forests of Jamaica. Kingston, Jamaica: The Jamaican Society of Scientists and Technologists.

Renton, K. (1998) Reproductive ecology and conservation of the Lilac-crowned Parrot (Amazona finschi) in Jalisco, Mexico. PhD thesis. The University of Kent at Canterbury, UK.

Ricklefs, R. E. (1967) A graphical method of fitting equations to growth curves. Ecology 48: $978-983$.

Ricklefs, R. E. (1969) An analysis of nesting mortality in birds. Smith. Contrib. to Zool. 9: $1-48$.

Saunders, D. A. (1982) The breeding behaviour and biology of the Short-billed form of the White-tailed Black Cockatoo Calyptorhynchus funereus. Ibis 124: 422-455.

Scott, W. E. D. (1891-1893) Observations on the birds of Jamaica, West Indies. Auk 8: 249256, 353-365; 9: 9-15; 369-375; 10: 177-181, 339-342.

Skutch, A. F. (1985) Clutch size, nesting success, and predation on nests of neotropical birds, reviewed. AOU Monogr. 36: 575-594.

Smith, G. T. and Saunders, D. A. (1986) Clutch size and productivity in three sympatric species of Cockatoo (Psittaciformes) in the southwest of Australia. Aust. Wildl. Res. 13: 275-285.

Snyder, N. F. R., Wiley, J. W. and Kepler, C. B. (1987) The parrots of Luquillo: natural history and conservation of the Puerto Rican Parrot. Los Angeles: Western Foundation of Vertebrate Zoology.

Snyder, N. F. R., McGowan, P., Gilardi, J., and Grajal, A., eds. (2000) Parrots: status, survey, and conservation action plan 2000-2004. Gland, Switzerland and Cambridge, U.K.: IUCN.

Stanback, M. T. and Koenig, W. D. (1994) Techniques for capturing birds inside natural cavities. J. Field Orn. 65: 70-75.

Stattersfield, A. J., M. J. Crosby, A. J. Long and D. C. Wege (1998) Endemic bird areas of the world. Cambridge, U.K.: Burlington Press (Birdlife Conserv. Series 7)

Stoleson, S. H. and Beissinger, S. R. (1997) Hatching asynchrony, brood reduction, and food limitation in a neotropical parrot. Ecol. Monogr. 67: 131-154.

Varty, N. (1991) The status and conservation of Jamaica's threatened and endemic forest avifauna and their habitats following Hurricane Gilbert. Bird Conserv. Internatn. 1: 135151.

Wainright, P., Gnam, R., Halanych, K. M., Burke, R., Wiley, J. W., Galvez, X., Eberhard, J. 
R., Amato, G. and Grassle, J. F. (in press) Proposed dispersal routes of the genus Amazona through the West Indies.

Walankiewicz, W. (1991) Do secondary cavity-nesting birds suffer more from competition for cavities or from predation in a primeval deciduous forest? Nat. Areas J. 11: 203-212.

Waltman, J. R. and Beissinger, S. R. (1992) Breeding behavior of the Green-rumped Parrotlet. Wilson Bull. 104: 65-84.

Weathers, W. W. (1996) Energetics of postnatal growth. Pp. 461-497 in C. Carey, ed. Avian energetics and nutritional ecology. New York: Chapman and Hall.

Weathers, W. W. and Sullivan, K. A. (1989) Nest attentiveness and egg temperature in Yellow-eyed Junco. Condor 91: 628-633.

Wiley, J. W. (1991) Status and conservation of parrots and parakeets in the Greater Antilles, Bahama Islands, and Cayman Islands. Bird Conserv. Internatn. 1: 187-214.

Wiley, J. W. and J. M. Wunderle, Jr. (1993) The effects of hurricanes on birds, with special reference to Caribbean islands. Bird Conserv. Internatn. 3: 319-349.

Wilkinson, L. (1990) SYSTAT: the system for statistics. Evanston: SYSTAT, Inc.

Wilson, K. A., Field, R., and Wilson, M. H. (1995) Successful nesting behavior of Puerto Rican Parrots. Wilson Bull. 107: 518-529.

World Resources (1998-99) Joint publication by The World Resources Institute, United Nations Environment Programme, United Nations Development Programme, and The World Bank. New York: Oxford University Press.

Wright, T. M., Toft, C. A., Enkerlin-Hoeflich, E., Gonzalez-Elizondo, J., Albornoz, M., Rodríguez-Ferraro, A., Rojas-Suárez, F., Sanz, V., Trujillo, A., Beissinger, S. R., BerovidesAlvarez, V., Gálvez, X., Brice, A. T., Joyner, K., Eberhard, J., Gilardi, J., Koenig, S. E., Stoleson, S. H., Martuscelli, P., Meyers, J. M., Renton, K., Rodríguez, A. M., SosaAsanza, M., Vilella, F. J, and Wiley, J. W. (in press) Nest poaching in Neotropical parrots. Conserv. Biol.

Wunderle, J. M., Jr. and Wiley, J. W. (1996) Effects of hurricanes on wildlife: implications and strategies for management. Pp. 253-264 in R. M. DeGraaf and R. I. Miller, eds. Conservation of faunal diversity in forested landscapes. London: Chapman and Hall (Conserv. Biol. Series 6).

SUSAN E. KOENIG

Windsor Research Centre, Sherwood Content P.O., Jamaica, W.I. E-mail: susankoenig@ cockpitcountry.com

Received 7 December 2000; revision accepted 10 June 2001 
